\title{
The Development of Protocols for Equitable Testing and Evaluation in Ocean Energy - A Three-Year Strategy
}

\author{
David M Ingram $^{1}$, Jose Luis Villate ${ }^{2}$, Cyrille Abonnel ${ }^{3}$ and Cameron Johnstone ${ }^{4}$ \\ ${ }^{1}$ Institute for Energy Systems, The University of Edinburgh, \\ Kings Buildings, Edinburgh EH9 3JL, United Kingdom \\ ${ }^{2}$ Robotiker Energía, Tecnalia, Parque Tecnológico, \\ Edificio 202. E-48170 Zamudio, Spain \\ ${ }^{3}$ Electricité de France, Direction Recherche et Développement, \\ 6, Quai Watier, 78401 Chatou, France \\ ${ }^{4}$ Energy Systems Research Unit, University of Strathclyde, \\ 16 Richmond Street, Glasgow GL1 1XQ, United Kingdom
}

\begin{abstract}
EquiMar (Equitable Testing and Evaluation of Marine Energy Extraction Devices in terms of Performance, Cost and Environmental Impact) is one of the first round of energy projects under the European Commissions 7th Framework Programme (FP7). The three year EquiMar project aims to deliver a suite of protocols for the evaluation of both wave and tidal converters, harmonizing testing and evaluation procedures across the wide range of available devices, accelerating adoption through technology matching and improving the understanding of both environmental and economic impacts associated with the deployment of devices. The EquiMar protocols will cover site selection, initial design, scaling up of designs, the deployment of arrays and environmental impact assessment as well as economic issues. EquiMar will build on existing protocols, e.g. UK DTI Marine Renewables Development Fund (MRDF) protocols for wave and tidal energy, and engage with international standards setting activities, e.g. IEC TC114.
\end{abstract}

Keywords: Ocean Energy Conversion, Renewable Energy, Protocol Development

\section{Introduction}

Most marine energy is too diffuse and too far from land to be economically exploited. Nearer shore it can be effectively captured for practical use, although at present operational ocean energy systems are mostly restricted to experimental or demonstration units [1] - There are currently 22 part-scale prototypes undergoing sea trials and 13 prototype devices being demonstrated, to date only one wave farm project is underway. Current technological developments and growing concern for global warming should lead to a more promising and reassuring outlook for ocean energy in the future.

Currently marine energy is not fully commercialised, indeed the recent AEA/SEI/IEA-OES report [1] identifies several barriers to future development in ocean energy. In particular there is "a lack of understanding regarding impacts on the environment” and "the comparison of different technologies is made difficult by the absence of internationally recognized standards for development, testing and measurement.” Clearly the need to address this has been identified by the EU Commission in the Framework 7 work programme (as topic ENERGY.2007.2.6.3) and by the IEC in establishing TC 114.

The EquiMar project will deliver a suite of protocols for the equitable evaluation of marine energy converters (tidal and wave). These protocols will harmonise testing and evaluation procedures across the wide variety of devices presently under development. The aim of such protocols is to accelerate adoption though enhancements of technology matching to the resource and to establish improved understanding of the environmental and economic impacts associated with the deployment of arrays of devices.

EquiMar will assess devices through a suite of protocols covering site selection, device engineering design, the scaling up of designs, the deployment of arrays of devices, the environmental impact, in terms of both biological \& coastal processes, and economic issues. A series of protocols will be developed through robust, auditable processes and disseminated to the wider community.

This paper describes the EquiMar project and the strategy selected to develop the protocols. 


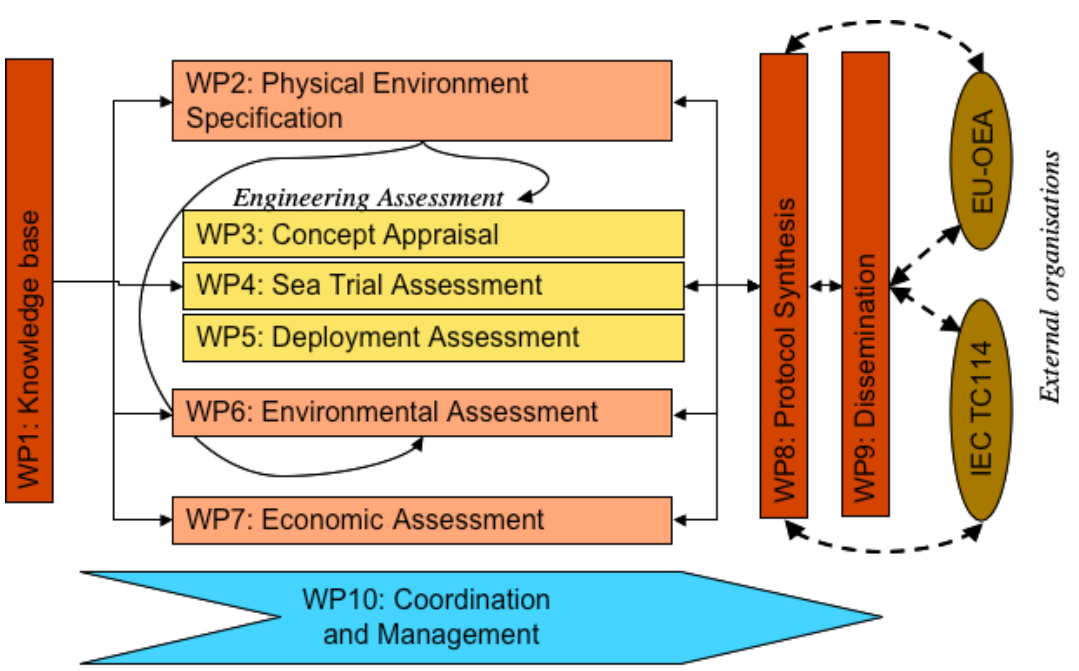

Fig. 1 EquiMar project work package structure

\section{The EquiMar Project}

The EquiMar project is split into ten work packages, six of which are directly concerned with the development of a draft protocol and the underpinning research necessary to deliver it. The draft protocols will be pass through a consultation and synthesis process, under the control of a seventh work package before being disseminated to the wider community. Fig 1 illustrates the structure of the project. The protocols fall into four distinct groups, namely Physical Environment Specification, Engineering Assessment, Environmental Assessment and Economic Assessment. The remaining work packages are concerned with the background knowledge and coordination activities.

\subsection{Physical Environmental Specification}

In the marine environment characterizing the performance of both wave and tidal stream devices is a difficult task, which depends on knowing the conditions at the location where each device is to be deployed. These conditions vary from point to point due to changes in water depth, bathymetry profile, geometry, exposure of the area, proximity to land, presence of other devices and structures and local meteorology. To understand these factors a two-stage approach is envisioned. Firstly a database of wave and tidal measurements will be assembled for different locations covering deep and shallow water conditions. This data will be used for the calibration of other models and also used to derive a number of "standard" sea conditions that can be used when conceptual designs are being tank tested. Whilst such standard test conditions will mostly apply to wave devices standard conditions for tidal testing, with a range of current speeds and turbulence intensities may also be specified.

The second stage will be to perform a number of detailed site-specific studies. The purpose of these studies will be to examine the local spatial and temporal variation of both current and wave conditions with the express aim of developing a general probabilistic methodology for site description. In these studies field observations (e.g. from wave rider buoys and acoustic Doppler current profilers, ADCPs), regional ocean models, and local models, e.g. SWAN [2], MIKE21 [3], and TELEMAC [4] will be used and guidance on site modelling will be developed.

\subsection{Engineering Assessment}

The approach to the engineering assessment of devices is based on a threefold strategy of proof of concept, medium scale seatrial demonstration and full scale array deployment.

The initial proof of concept stage is based on initial numerical and computational assessment and a series of model tank tests to demonstrate that the prime mover of the proposed device performs in accordance with its design, followed by an assessment of the capacity of the device against some standard sea conditions (which will defined by work package 2). These tests allow the device to be tested under carefully controlled repeatable conditions and a careful scientific study of the devices performance to be made. It is important that different laboratories take a consistent approach to such testing so that operators, funding and certification agencies can make direct comparisons between devices, without the need to consider "laboratory effects". Several of the project partners (including the Universities of Aalborg, Strathclyde and Edinburgh, and the Français de recherche pour l'exploitation de la mer) have significant experience in the tank testing of models and this experience will be synthesized into a best practice protocol for conducting tests, recording data and reporting results. The model testing work package will also consider how computer models (for example computational fluid dynamics codes) can be used in the initial testing phase.

When device development begins, and the device leaves the laboratory for the open sea, an element of control on the testing and evaluation procedures is inevitably lost. In particular designers must accept the energy flux input conditions that occur naturally, rather than having the luxury to generate them as and when required. This means sea trial schedules and analysis methodologies must be very carefully planned and rigorously followed if the performance and behavior of the machines, particularly at different settings, are to be verified and improved under real operating conditions. Such procedures are essential if this work is to be achieved in a reasonable short time frame. Knowledge of the physical environment (from work package 2) is of paramount important in this programme planning.

The move from housed, indoor test tanks to semi-exposed, scaled outdoor test sites, then to fully exposed, outdoor sites is usually associated with the increase in the size, or scale, of the ocean energy converter. This development phase, therefore, covers 
devices from, circa, tenth scale to full size prototype solo machines that may, or may not, be grid connected. Even the large, i.e. $1 / 4$ scale, machines will, however, be fitted with fully functioning power take-off (PTO) units and electrical generators, rather than the simple energy dissipaters, or damping simulators, routinely used in the hydraulic tank facilities. A close association with the experiences and information produced by the work package on Tank Testing Practices, will aid understanding of the information to be generated at these larger sizes, assist in developing the data analysis packages required and the presentation routines needed. Verification of the smaller scale results is important, as this will vindicate the design decisions taken on these test results.

Ocean energy device developers and the future operators of power production parks have already expressed the necessity in establishing common methods and classification approaches that will assist in the comparison of the performance of different types of devices in similar seaways or expected performance indicators for spatially or temporally separated conditions. It is critical that this work is done in close liaison with device developers in order to establish the required standard monitoring approaches, best practice sea trial techniques and analysis \& presentation methodologies. Only once the performance of a single device has been established should the next stage of assessment - array deployment be undertaken.

The final engineering assessment work package deals with array deployment. There are important implications of array deployment for both wave and tidal devices - in the case of tidal rotors; wake interference effects will change the efficiency of down stream rotors [5,6] and the greater "blockage" caused by an array will affect the available resource [7]. In wave devices on the other hand radiated waves can cause resonance effects that may be either beneficial or detrimental to the performance of the array [8,9]. In order to predict the performance of an array of devices these effects must be taken into account.

Another issue affecting array deployments is the impact of the array on the maintenance, reliability and survivability of the individual devices in the array. A simple statistical analysis will show that the probability of the failure of a single device in a large array is significant and from an engineering perspective the consequences of such a failure must be explored. For example should a device break free of its moorings it could collide with other devices in the array causing further failures. Whilst construction standards exist for single devices (e.g. DNV [10]) this guidance needs to be extended to the operation of arrays.

The final issue for arrays of devices relates to the quality of electricity delivered to the grid. The marine sector can learn a lot of lessons from the offshore wind farms, specific work is required on arrays of marine energy converters - the principal grid connection variants for wave and tidal farms needs to be established, guidance on the suitability and installation of electrical connection configurations is required, as is guidance on the appropriate offshore voltages and the use of substations. Only once these have been completed can the existing wave-to-wire models be extended to produce an appropriate tool for the evaluation of specific site designs.

\subsection{Environmental Assessment}

Despite the fact that the environmental impacts of deploying marine energy converters are not fully understood in many countries this is the most tightly regulated area. To date only a few Environmental Impact Assessments (EIAs) have been carried out and only for small pilot plants. The assessment of these impacts is complex due to both the variety of devices and the different ways they interact with the benthic environment. A further conflict exists in that most EIAs are aimed at gaining consent rather than environmental protection - on one hand EIAs are a legislative requirement, but on the other, their findings could be used as proof of sustainability, leading to increased public acceptance. For example, it may be necessary to place a no-take area around a marine energy farm providing a refuge for stressed fish stocks. Furthermore such an approach would lead to increased interest by investors and governments, who have traditionally seen environmental concerns as a barrier to development.

EquiMar aims to develop a robust scientific protocol for the conducting an EIA including guidance on when baseline studies are needed, procedures for monitoring environmental impact post deployment and appropriate mitigation measures. In addition field studies will be undertaken to consider the impact of device deployment on large vertebrates. Presently there is significant concern, amongst both developers and the general public, over the possible collision of marine mammals with marine energy converters - this risk depends on both the potential for avoidance behavior and the chance of encounter. Encounter models which although normally used for predator-prey modelling have been successfully applied to bird collision with wind turbines [11], and to examine the impact of seismic surveys on marine mammals [12] will be adapted for the marine energy extraction. The model, to be developed by the Scottish Association for Marine Sciences (SAMS) and the Sea Mammal Research Unit of the University of St Andrews, will utilize data from real animals with the ultimate aim of developing a modelling tool, which can be used to assess the impact of device deployment in varying locations.

Finally these techniques will be applied to sites such as the WaveHub (off the Cornish coast of the UK), EMEC (Orkney, Scotland), Galloway Bay (Ireland) and the Portuguese Pilot Zone.

\subsection{Economic Assessment}

The final set of protocols will deal with the economic assessment of marine energy converters. A systematic approach is needed which includes realistic estimates of component costs, deployment and maintenance costs, etc. It is important for the emerging industry that such a methodology generates reasonable estimates of the costs of operation and ownership leading to justifiable and believable estimates of the final $\mathrm{kW} / \mathrm{h}$ price. In the current political climate there is significant pressure to offer unjustifiable $\mathrm{kW} / \mathrm{h}$ prices, which if we fail to deliver will significantly damage the industry. There is a clear need then to develop methods for assessing how the economic viability of the main types of marine energy technology may change with increasing scale of deployment. In order to distinguish between technologies the focus must be on evaluating the essential infrastructure costs associated with different types of marine energy device and the assessing the scope for reducing cost of electricity by optimizing device performance. This will provide a framework for assessing the long-term viability of designs that are at differing stages of development. This work package will develop a tool set that will be of considerable use to policy makers and marine energy investors.

Whilst there is an obvious economic driver to consider models that estimate the monetary cost of generation for different technologies, there is also a clear need to examine the carbon footprint of each technology - a process closely linked with the 
Environmental Assessment work package. Knowledge of the carbon footprint will allow an assessment of additional financial benefits that may be available through carbon trading schemes. The authors note that the audit methods needed to assess the reliability and construction costs of individual devices can also allow a carbon footprint audit to be made at the same time (e.g. Rankine, Chick and Harrison, [13]).

\subsection{Engagement with 3rd Parties}

If successful protocols are to be developed, and adopted by the wider community they must be based on a broad consensus of opinion. The protocols developed must reflect (i) the current state of academic understanding (ii) the needs of the machine developers (iii) external national and certification bodies (iv) developments from research and technical developments within the rest of EquiMar. It is also important that the protocols should reflect the possible extension to international standards in due course and to this end engagement with certification organizations (in this case Det Norkse Veritas) is critical. The Final EquiMar protocols will address assessment in the five topics described, with separate output for wave and tidal energy where appropriate. A key outcome will be the synthesis of the individual outputs into a single document, which will describe a methodology to asses the appropriateness of individual technologies to specific sites, which will necessarily require a combination of technical, economic and environmental assessment.

Within each technical work package there will be a specific deliverable to develop the appropriate draft protocol. These will draw together the prior knowledge, identified at the start of the project with the new understanding from the technical work packages. This will be validated and modified by a quantified survey of stakeholders and external experts. To ensure flow of output from each work package there will be a "review board" consisting of work package leaders and suitable external experts. The group itself will act as a mechanism for ensuring compatibility and equivalence between the different protocols.

As well as external experts the draft protocols will be circulated to the end user community for comment, this will be achieved by dissemination activities at international conferences (e.g. the International Conference on Ocean Energy organized midOctober 2008 in France by two EquiMar partners: Electricité de France and the Institut Français de recherche pour l'exploitation de la mer), through circulation of stake-holders by the European Ocean Energy Association (EU-OEA), through National R\&D projects (e.g. the UK Engineering and Physical Science Research Council's SuperGen Marine Project) and by engagement with international organizations such as the IEA-OES.

In addition several partners in the project are members of their respective National mirror committees for IEC TC 114. This IEC technical committee was formed at the same time as the EquiMar proposal was being written to start the process of developing internationally accepted standards for ocean energy and it is hoped that the standards process will inform (and be informed by) the EquiMar project.

\section{Conclusions}

The marine energy conversion industry is currently in its infancy, with a large number of different emerging technologies for both wave and tidal energy conversion. It is critical that standards and protocols are developed to allow policy makers, utility companies, device owners and developers, consenting agencies, insurers and investors to make fair and equitable assessments of these technologies. There is a clear need for such protocols which must be based on the current state of the art and reflect the concerns of both developers and other stakeholders. The development of such protocols is not a quick process as the development of a consensus takes time, but the EquiMar project is timely since it will run in parallel with the work of the IEC technical committee and the associated National mirror committees.

\section{Acknowledgments}

The first author wishes to acknowledge wishes to acknowledge support for his position from the Scottish Funding Council and for their support of the Joint Research Institute in Energy with the Heriot-Watt University as a component part of the Edinburgh Research Partnership.

Funding from the EU Commission for the EquiMar project (Grant Agreement No. 213380) is acknowledged as is the help in preparing the project proposal of the partner institutions - The University of Edinburgh, Fundación Robotiker, University of Strathclyde, Electricité de France SA, EU Ocean Energy Association, University of Exeter, University College Cork, Wave Energy Centre, The University of Manchester, Southampton University, Institut Français de recherche pour l'exploitation de la mer, Consiglio nazionale delle ricerche: Instituto di Scienze Marine, Det Norske Veritas, Teamwork Technology, Pelamis Wave Power Ltd, European Marine Energy Centre, Wave Dragon, Uppsala University, Sea Mammal Research Unit, Scottish Association of Marine Sciences, Feisty Productions Ltd, Aalborg University, and Actimar.

\section{References}

[1] AEA Energy \& Environment, 2006, Review and Analysis of Ocean Energy Systems Developing and Supporting Policies, a report on behalf of Sustainable Energy Ireland for the IEA-OES

[2] Booij, N., Holthuijsen, L.H. and R.C. Ris, 1996, “The SWAN wave model for shallow water”, Proc. 25th Int. Conf. Coastal Engng., Orlando, USA, Vol. 1, pp. 668-676

[3] Danish Hydraulic Institute, 2003, MIKE21 Hydrodynamic module, Scientific Documentation.

[4] Hervouet, J.M., and Bates, P., 2000, “The TELEMAC modelling system”, special issue, Hydrol. Process., Vol. 14, pp. 22072363.

[5] Bryden, I.G., Couch, S.J., Owen, A. and Melville, G., 2007, “Tidal Current Resource Assessment”, Proceedings of the Institution of Mechanical Engineers Part A: Journal of Power \& Energy, Vol 221 pp 125-135 
[6] Bahaj, A.S., Myers, L.E., Thompson, M.D., and Jorge, N., 2007, “Characterizing the Wake of Horizontal Axis Marine Current Turbines”, Proc. European Wave and Tidal Energy Conference (EWTEC), Porto, Portugal, Paper No 1076.

[7] Couch, S.J. and Bryden, I.G., 2004, “The impact of energy extraction on tidal flow development”, Proc. 3rd International Conference on Marine Renewable Energy, Blyth, UK.

[8] Child, B.F.M., and V. Venugopal, V., 2007, "Interaction of waves with an array of floating wave energy devices”, Proc. European Wave and Tidal Energy Conference (EWTEC), Porto, Portugal, Paper No 1059.

[9] Fitzgerald, C., and Thomas, G., 2007, “A preliminary study on the optimal formation of an array of wave power devices”, Proc. European Wave and Tidal Energy Conference (EWTEC), Porto, Portugal, Paper No 1124.

[10] Det Norske Veritas, 2005, Guidelines on design and operation of wave energy converters, report commissioned by the Carbon Trust.

[11] Fox, A.D., Desholm, M., Kahlert, J., Christiansen, T.K., and Petersen, I.K., 2006, “Information needs to support environmental impact assessment of the effects of European marine offshore wind farms on birds”, Ibis, Vol 148, Supplement 1, pp. 129-144.

[12] Gordon, J., Gillespie, D., Potter, J., Frantzis, A., Simmonds, M.P., Swift, R., and Thompson D., 2003, “A review of the effects of seismic surveys on marine mammals”, Marine Technology Society Journal, Vol. 37, No. 4, pp.16-34

[13] Rankine, R.K., Chick, J.P, and Harrison, G.P, 2006 “Energy and carbon audit of a rooftop wind turbine”, Proceedings of the Institution of Mechanical Engineers, Part A: Journal of Power and Energy, Vol. 220, No. 7, pp. 643-654.

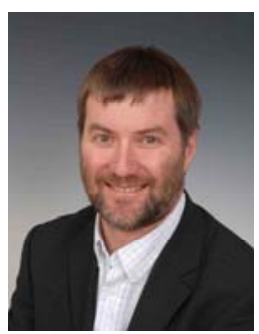

David Ingram joined the Institute for Energy Systems at the University of Edinburgh in 2006 as a Reader. Previously Reader in Scientific Computation at Manchester Metropolitan University (MMU), his research involves the development of novel CFD codes for highly transient problems involving discontinuities and sharp fronts. He is Coordinator of EquiMar, and a co-manager of the EPSRC SuperGen Marine project, he also led MMU's work on violent wave overtopping under the EPSRC VOWS and EU CLASH projects. He gained his $\mathrm{PhD}$ from MMU in 1992 and has subsequently published over 60 publications in international journals and conferences. He has given invited seminars at the Universities of Hokkaido, Osaka City and Kyoto and to the Proudman Oceanographic Laboratory.

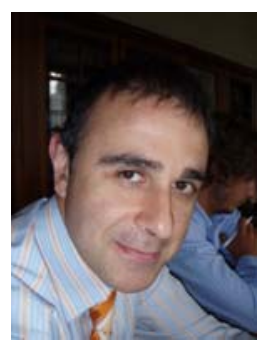

Jose Luis Villate has the degree of Physics Science (1991, Universidad del Pais Vasco) and a MSC in Advanced Manufacturing Technologies (1992, Escuela Técnica Superior de Ingeniería de Bilbao). Since then, he works in the Research Centre ROBOTIKER where currently is Head of the Marine Energy Section. He has worked in many projects related to electronics, digital control systems and power converters for the integration of Renewable Energy Sources (RES) into the grid. From 1998 to 2000, he was lecturer of Industrial Control in the Engineering School of Deusto. He is PhD student in the Engineering School of Bilbao, working on the field of power converters for RES. He has authored more than 20 papers and conference communications in national and international forum. He is co-author of 4 patents, 3 of them for renewable energy applications.

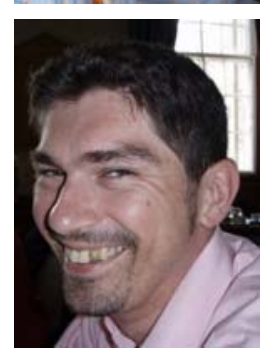

Cyrille Abonnel “ingénieur” from the Hydraulics School within the French Toulouse National Polytechnic Institute (INP-ENSEEIHT, 1998), has been managing the development of marine renewable activities within EDF R\&D since 2001, to facilitate the deployment of first prototypes in the French and UK waters, like the SEAGEN project (with Marine Current Turbines Ltd) EDF Energy, the UK subsidiary of the Group, is a partner of. Representative of EDF SA in the European Coordinated-Action on Ocean Energy (FP6). During his first position within EDF R\&D (1998-2000) he worked in Vietnam to increase research collaborations with Vietnamese bodies on flood management projects. Technical consultant for the French Embassy, he was also in charge of the hydraulic analysis of one of the feasibility studies within the Red River Basin Water Resources Management Asian Development Bank Project.

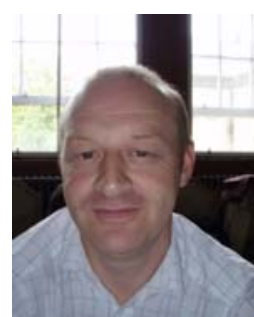

Cameron Johnstone is a senior lecturer and Director of the University of Strathclyde's, Energy Systems Research Unit. He is an electro-mechanical engineer specialising in mechanical power capture and conversion utilising turbo-machinery. Relevant research projects include: EPSRC SUPERGEN-Future Electrical Networks; Supergen Marine; EC FP VI Co-ordinated Action in Ocean Energy (CA-OE); and as project manager and PI on a Scottish Enterprise Proof of Concept that built and sea-deployed an intermediate scale Contra-Rotating Marine Turbine. 